Review

\title{
Molecular biology of breast cancer metastasis Clinical implications of experimental studies on metastatic inefficiency
} Ann F Chambers, George N Naumov, Sharon A Vantyghem and Alan B Tuck* London Regional Cancer Centre and *London Health Sciences Centre, London, Ontario, Canada

Received: 7 February 2000

Revisions requested: 7 February 2000

Revisions received: 10 February 2000

Accepted: 20 March 2000

Published: 21 July 2000
Breast Cancer Res 2000, 2:400-407

(c) Current Science Ltd (Print ISSN 1465-5411; Online ISSN 1465-542X)

\begin{abstract}
Recent technological advances have led to an increasing ability to detect isolated tumour cells and groups of tumour cells in patients' blood, lymph nodes or bone marrow. However, the clinical significance of these cells is unclear. Should they be considered as evidence of metastasis, necessitating aggressive treatment, or are they in some cases unrelated to clinical outcome? Quantitative experimental studies on the basic biology of metastatic inefficiency are providing clues that may help in understanding the significance of these cells. This understanding will be of use in guiding clinical studies to assess the significance of isolated tumour cells and micrometastases in cancer patients.
\end{abstract}

Keywords: in vivo videomicroscopy, isolated tumour cells, metastatic inefficiency, micrometastases, tumour dormancy

\section{Introduction}

Breast cancer is the leading cause of death from cancer in women, with an estimated 300000 deaths worldwide attributed to breast cancer in the year 1990 $[1,2]$. The vast majority of these deaths are due to metastasis. Women whose breast cancer is detected and treated prior to metastatic spread of cancer cells from the primary site have a higher probability of being cured of their disease, and early detection is thus of major importance. When breast cancer is detected after it is known, or suspected, to have metastasized, treatment decisions are more complex and prognosis is less favourable.
Metastatic spread has traditionally been assessed by histological examination of lymph nodes for the presence of metastatic lesions. However, recent technical improvements in the ability to detect cancer cells at distant sites, in blood, bone, sentinel lymph nodes and other tissues, and either as isolated cancer cells or as small foci of cells, have made treatment decisions even more complex. There are conflicting reports as to the clinical significance of such isolated cancer cells and small foci [ $\left.3^{\circ}\right]$. Should they be considered as metastases, with the potential to grow to clinically relevant size, or are they in some cases unrelated to clinical outcome? Should the presence of any cancer cells at sites distant from a primary tumour be

IVVM = in vivo videomicroscopy. 
considered as evidence of metastasis, and the patient thus treated aggressively? This ability to detect smaller micrometastases, and smaller numbers of isolated tumour cells, has indeed called into question the definition of 'metastasis' [4*0]. The ability and likelihood of such cells to grow to form clinically relevant metastases must be clarified before the ability to detect them can be used clinically in an appropriate manner.

One solution to this dilemma is to conduct clinical trials to determine the significance of cancer cells detected at sites distant from the primary tumour and their ability to predict the course of disease. Such studies clearly are necessary, but long-term follow-up periods will be required to validate the findings. Furthermore, the answers will probably vary with the type of tumour, features of the primary tumour (grade, etc) and various markers that are expressed by cells both in the primary tumour and at the distant sites.

Another complementary approach comes from a growing understanding of the basic biology of the metastatic process. Cancer metastasis is known to be an inherently inefficient process, from several lines of evidence, both clinical and experimental [5]. Clinically, large numbers of circulating cancer cells can be detected in blood of cancer patients, with very small numbers of metastases resulting $[6,7]$. Similarly, in experimental studies, large numbers of cancer cells can be present in the circulation, either from implanted primary tumours or cancer cells injected into the circulation, and again relatively few metastases may result [8-10]. We and our colleagues have been using experimental in vivo videomicroscopy (IVVM) procedures in order to understand the biological and molecular mechanisms of metastasis (for review $\left.\left[11,12^{\circ}, 13,14,15^{\circ}\right]\right)$. We have also developed quantitative procedures to measure formally the efficiency of specific steps in the metastatic process $[16,17]$. Recent work by others, which is discussed below, adds important information from independent, complementary experimental approaches. Together these studies are beginning to allow clarification of which steps in the process contribute significantly to metastatic inefficiency, and some of the molecular mechanisms responsible. These studies can provide a conceptual framework for understanding the clinical significance of cancer cells detected at various points along the metastatic cascade. This understanding will also aid in guiding clinical studies to assess the significance of isolated tumour cells and micrometastases in specific cancers.

In the present review, we describe some of the experimental in vivo procedures that we have used to clarify mechanisms of the metastatic process and to determine the efficiency of specific steps, and we summarize findings from these studies. We describe some recent findings from other investigators, which also shed light on metastatic inefficiency and variability. We conclude that some steps in metastasis appear to be quite inefficient, and the ability to accomplish these steps seems to vary markedly between cancer cells of high versus low metastatic ability, as well as between different organs. In contrast, other steps appear to be efficiently carried out, with little dependence on the ultimate metastatic ability of the cells. The clinical implications of these experimental findings are considered. We propose that these conclusions may help in addressing the current clinical dilemma of interpreting the significance of isolated cancer cells and micrometastases in patients, and that they suggest appropriate directions for future research.

\section{Experimental approaches for studying sequential steps of metastasis \\ In vivo videomicroscopy}

IVVM procedures permit direct observations of sequential steps of the process of metastasis, as they occur in real time in living experimental animals. The equipment required is relatively straightforward, and includes an inverted microscope with epifluorescence illumination capability, connected to a video camera, computer and a video recorder. Oblique transillumination, provided by a fibre-optic light source, permits clear visualization of tissues and the microcirculation. We have used this approach to observe steps in metastasis after injection of cells into the circulation ('experimental metastasis') for a variety of cancer cell types in several target organs. We are extending these studies to observations of steps in metastasis of cells implanted orthotopically to form primary tumours ('spontaneous metastasis'). IVVM methodologies that we have developed and used have been described in detail previously (for review $\left[11,12^{\circ}, 13\right.$, $\left.14,15^{\circ}\right]$ ), so only a brief summary is provided here.

Fig. 1 presents an example of the sort of in vivo images that can be obtained, in the context of ongoing experiments in our laboratory on spontaneous metastasis of breast cancer cells (Vantyghem et al, unpublished data). Fig. 1a shows the vascular and lymphatic circulatory structure within a normal (nontumour-bearing) murine mammary fat pad; in the video recording from which this view was derived, lymphatic and blood flow patterns within the mammary gland can readily be observed. Fig. $1 \mathrm{~b}$ shows the structure of a lymph node draining this mammary fat pad; in the original video recording, the three-dimensional structure can be visualized by focusing up and down through the lymph node.

Visualization of cancer cells by IVVM requires that the injected cells be labelled with a marker to help distinguish them from the surrounding normal tissue. We have used three types of cell markers: naturally expressed endogenous products (such as melanin; eg $[16,17]$ ), exogenously added cytoplasmic labels (Calcein-AM [Molecular Probes, 

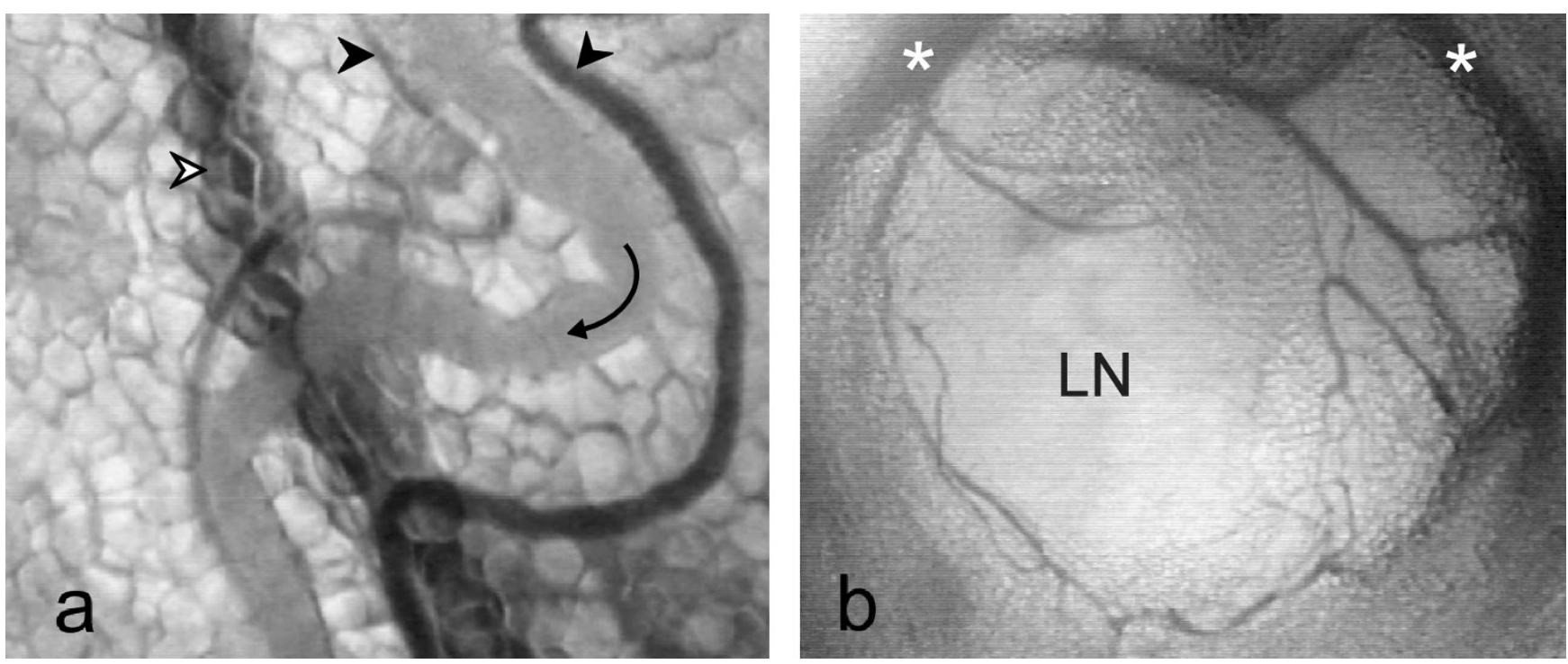

IVVM images of normal (nontumour-bearing) murine mammary fat pad and lymph node. (a) Mammary fat pad, viewed with IVVM, showing threedimensional structure of vessels and tissue. Direction of lymphatic flow is indicated by the arrow located within the lymphatic vessel $(\rightarrow)$. Flow within the adjacent blood vessels $(\triangleright)$ was in the same direction. Another vessel (indicated with open arrowhead), was out of the plane of focus and could be resolved by focusing up and down through the tissue. 200x. (b) The inguinal lymph node (LN) found within mammary fat pad \#4 where a large internal mammary vessel (*) branches. 40x.

Eugene, Oregon, USA] or virus-sized fluorescent 'nanospheres' [18,19]), and transfected endogenous markers (green fluorescent protein [20]). Fluorescently labelled cells can be injected via a blood vessel that feeds the organ of interest. For example, in order to study metastatic growth in liver, cells can be injected into a mesenteric vein (we have observed that injection into the spleen, as used previously by others to target liver, also results in a large influx of leucocytes into the liver, so we have avoided that route). Other routes can be used to target cells for observations in lung or muscle, etc. At various time points later, animals are surgically opened in order to partially expose the organ with its blood flow intact, and the anaesthetized animal is positioned on the inverted microscope with the exposed organ gently pressed against a coverglass above the objective lenses. This positioning keeps the lower surface of the organ stationary and in focus, in spite of motion in the rest of the organ due to respiration. Transillumination is used to identify stromal cells, red blood cells, leucocytes, and the anatomical structures of the organ and its microcirculation. Epifluorescence illumination permits positive identification of cancer cells within a field of view. Real-time images are captured using a video camera with extended red sensitivity, and are video recorded. This approach has permitted detailed and direct observation of sequential steps in 'experimental' metastasis as they occur in vivo.

Other laboratories have used a variety of in vivo recording procedures and have obtained results that complement those that we have obtained. For example, Farina et al [21] described a confocal in vivo imaging approach, and have used this to make observations on cell motility in orthotopically implanted mammary tumours in rat. Sckell et al [22] used in vivo video observation techniques, notably for clarifying vascular patterns in tumours. Scherbarth and Orr [23] used an experimental set up similar to that described above, and have provided information on the cytokine-dependence of the position of cell arrest in liver.

\section{Quantification of metastatic inefficiency}

In order to be able to quantify metastatic inefficiency and the loss of cancer cells at specific steps in the metastatic process formally, we developed an 'accounting' technique that is able to measure survival of cancer cells at various times after their injection into the circulation of experimental animals $[16,17]$ (for review $\left[12^{\circ}, 1^{\circ}\right]$ ). For this purpose it is necessary to express the number of cells observed (per sample volume of tissue) relative to the number of cells originally delivered to that volume. Inert plastic fluorescent microspheres $(10 \mu \mathrm{m}$ diameter) are included in the cell suspension at a known cell:microsphere ratio (for example, 1 microsphere per 10 cells). After injection, the microspheres are trapped by size restriction in the microcirculation, where they permanently remain. Thus, at any time after injection, the total number of microspheres that are present in an observed tissue volume provides a reference to the number of cancer cells that originally arrived in the same region. The percentage of cells surviving to that point in time can then be calculated by following equation. 
Figure 2

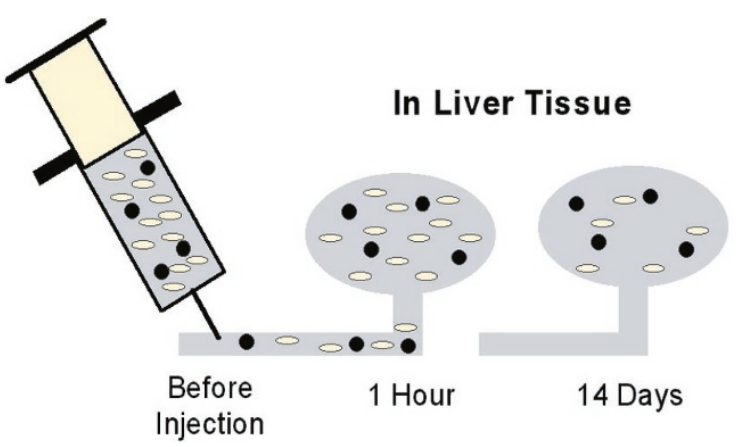

\begin{tabular}{|c|c|c|c|}
\hline \# cells & 12 & 11 & 5 \\
\hline \# microspheres & 4 & 4 & 4 \\
\hline $\begin{array}{l}\text { Cell } \\
\text { survival }\end{array}$ & $100 \%$ & $92 \%$ & $42 \%$ \\
\hline
\end{tabular}

Cell 'accounting' procedure for quantifying in vivo cell survival and metastatic efficiency. Inert plastic fluorescent microspheres (approximately $10 \mu \mathrm{m}$ ) are included in a cell suspension, in a known cell : microsphere ratio. The suspension is injected intravenously to target an organ (eg mesenteric vein to target liver). The microspheres remain indefinitely where they arrest in the microcirculation, providing a reference marker for the number of cells that originally reached that volume of tissue. Based on cell : microsphere ratios at later times, the percentages of surviving cells can be calculated (see example provided).

Cell : microsphere ratio in the liver after injection

Cell : microsphere ratio in the syringe before injection $\times 100 \%$

The same principle can be used to calculate the survival of cells even after they have begun to grow to form metastases, because metastases have been shown to be clonal in origin $[24,25]$. This technique may be used in conjunction with IVVM for observations of superficial regions of organs, or after fixation the tissue may be sampled throughout its entirety using 30-50 $\mu \mathrm{m}$ thick sections (eg [17]). Fig. 2 presents a diagram of this 'accounting' procedure and provides an example of how metastatic efficiency is calculated, as percentage cell survival at various times after injection, relative to the number of cells delivered to a tissue volume.

In combination, IVVM and cell 'accounting' techniques provide a high-resolution means of quantifying metastatic efficiency at sequential steps in the metastatic process. The proportion of injected cells that survive in the circulation, arrest in an organ, extravasate and survive in the tissue (as dormant solitary cells, early micrometastases, or progressively growing metastases) can be formally quantified, and the behaviour of cells at these steps in the metastatic process can be observed at high resolution.

\section{Metastatic inefficiency: conclusions from recent experimental studies}

Our results using the IVVM and cell 'accounting' procedures described above, with a variety of cancer cell types injected into the circulation in order to target various organs in experimental mice (as well as chicken embryos), have produced a remarkably consistent picture of the metastatic process and steps that appear to contribute to overall metastatic inefficiency. The experimental findings are not reviewed in detail here, because these are summarized in several recent reviews $\left[11,12^{\bullet}, 13,14,15^{\circ}\right]$. Instead, we outline our conclusions from these studies, bearing in mind that these are generalizations based on specific experiments, and that exceptions to these conclusions may well exist.

We have found that cells survive in the circulation with high efficiency (often greater than $80 \%$ of the original cell inoculum). This survival can be equally high in organs with high and low circulatory pressure (eg murine muscle, liver, lung; chick embryo chorioallantoic membrane). Similarly, survival in the circulation does not appear to depend on the degree of malignancy of the cells, with cells of high and low malignancy surviving equally well. Cells arrest initially in the target organ on the basis of size constraints, with cancer cells (which are often much larger than red or white blood cells) travelling in the circulation until they are arrested in microcirculatory vessels. This process of arrest is also highly efficient, with very high cell survival, and appears to be independent of the malignant potential of the cells.

We also have found that extravasation, the escape of cells from the circulation, is highly efficient, with greater than $80 \%$ of cells successfully completing this process. This finding was independent of cancer cell type or degree of malignancy of the cells. Indeed, we found that metastatic, ras-transformed NIH3T3 fibroblasts, control NIH3T3 cells, and even primary culture normal mouse embryo fibroblasts all extravasated with high efficiency and similar kinetics [26]. Thus, to this point in the process of 'experimental' metastasis (ie from intravenously injected cells [27 ${ }^{\circ}$ ) all steps appear to be completed with high efficiency, and independent of the degree of metastatic ability of the cells.

Once cells have completed extravasation, however, they appear much less efficient and more variable at completing subsequent steps in the metastatic process. In a detailed study of metastatic inefficiency of B16F1 murine melanoma cells injected to target liver [17], we found that more than $80 \%$ of injected cells survived in the circulation, arrested in the microcirculation, and successfully extravasated. However, only a small subset of extravasated cells began to grow (approximately $2 \%$ of injected cells), and only a subset of micrometastases that began to grow persisted in their growth to form large metastases (approximately $0.02 \%$ of injected cells). We are finding similar patterns for other cell 

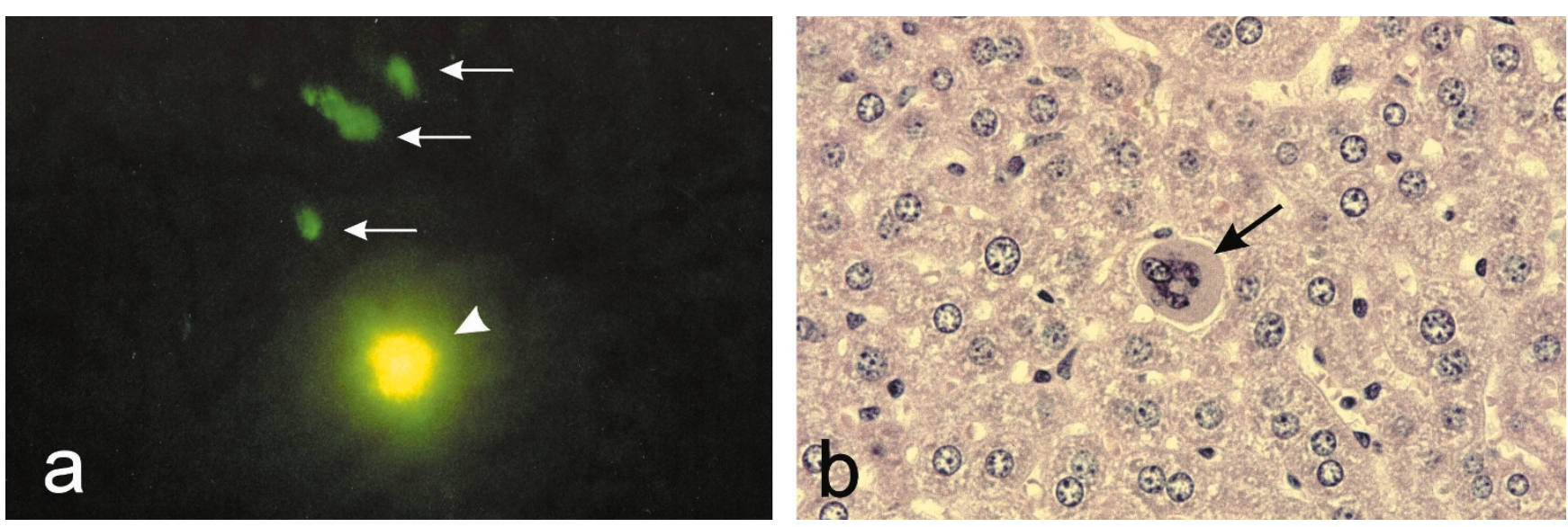

In vivo detection of solitary mammary carcinoma cells in murine experimental metastasis model. (a) Solitary murine mammary carcinoma (D2.OR) cells $(\rightarrow)$, fluorescently labelled, are present within normal liver tissue 11 weeks after intravenous injection to target the liver. In close proximity to the cells is a fluorescent 'accounting' microsphere $(\triangleright)$, approximately $10 \mu \mathrm{m}$ in diameter. The image was obtained by IVVM using epifluorescence plus transillumination. (b) Similar solitary mammary carcinoma cell $(\rightarrow ; \sim 10-15 \mu \mathrm{m}$ in diameter) in murine liver, 11 weeks after injection, detected by haematoxylin and eosin staining.

lines and organs, such as the following: B16F10 cells in lung [28]; mammary carcinoma cells of high versus low metastatic ability in liver (Naumov et al, unpublished data); and ras-transformed and control fibroblasts in liver (Varghese et al, unpublished data). The details of the percentage efficiency of postextravasation growth appears to vary for different cell lines and organs. These variations (rather than variations in delivery of cells to different organs) seem to be responsible for much of organ-specific metastasis (for discussion $\left.\left[14,1^{\circ}\right]\right)$. However, the generalizations that early steps (survival in the circulation, arrest in the microcirculation, extravasation) are efficiently completed, while later steps of initiation and persistence of growth after extravasation are inefficient and variable depending on the cell line and organ, seem to be consistent.

In addition, we have repeatedly observed isolated tumour cells persisting in secondary sites after extravasation, often for long periods of time. These numbers can be quite high, and may not be related to the metastatic ability of the cell line. For B16F1 cells in liver, we found that 36\% of injected cells persisted in a dormant state (ie negative for either proliferation/Ki67 or apoptosis/TUNEL) in the organ for the full 2-week period of observation, whereas a smaller subset of cells grew to form metastases [17]. In addition, the evidence suggested that cells that initiated division were more vulnerable to loss than cells that remained dormant. Similar dormant cells have been observed in murine mammary carcinoma cell lines that were injected to target them to liver, up to 11 weeks after cell injection, as detected both in vivo by their retention of fluorescent nanospheres (which are diluted out by cell division) as well as by histology (Naumov et al, unpublished data). Surprisingly, much larger numbers (approximately $80 \%$ of the injected cells) of undivided, dormant cells were detected in a poorly metastatic cell line (D2.OR) compared with a highly metastatic one (D2A1). Fig. 3 shows the appearance of such dormant cells, detected by their fluorescence (Fig. 3a) and histologically (Fig. 3b). Collectively, the results from several cancer cell lines suggest that dormant cells may persist in tissues, and may fail to progress to form metastases.

Recent studies on metastasis-suppressor genes support the idea that the presence of cancer cells in distant organs is not necessarily predictive of their ability to grow to form metastases (for review [29]; Yoshida et al, unpublished data). For both prostate cancer and melanoma models, metastasis-suppressor genes have been shown $\left[30^{\circ}, 31^{\circ}\right]$ to result in growth suppression of cells that have not lost their ability to disseminate to distant organs. The clear clinical implication of this conclusion, derived independently from the quantitative studies on metastatic inefficiency described above, and studies on metastasissuppressor genes, is that detection of cancer cells in secondary organs may not be predictive of their ability to grow to form metastases.

Our studies to date have not examined the earliest step in the process: intravasation of cells from a primary tumour. However, Farina et al [21] have used green fluorescent protein-labelled rat mammary carcinoma cells implanted orthotopically into rat mammary fat pads. Using this model, this group recently has compared highly with poorly metastatic cell lines for their ability to intravasate [32]. They found that the intravasation process appeared to be 
Figure 4

\begin{tabular}{|c|c|c|c|}
\hline \multicolumn{2}{|c|}{ Steps in metastatic process } & Efficiency & $\begin{array}{l}\text { Is efficiency related to } \\
\text { metastatic ability? }\end{array}$ \\
\hline Intravasation & \% & Inefficient & Yes \\
\hline $\begin{array}{l}\text { Survival in } \\
\text { the circulation }\end{array}$ & & Efficient & No \\
\hline Arrest in organ & & Efficient & No \\
\hline Extravasation & & Efficient & No \\
\hline $\begin{array}{l}\text { Survival of cells } \\
\text { after extravasation }\end{array}$ & $\theta^{\infty}$ & Inefficient & Yes \\
\hline $\begin{array}{l}\text { Initial growth of } \\
\text { cells after extravasation }\end{array}$ & 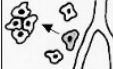 & Inefficient & Yes \\
\hline Persistence of growth & & Inefficient & Yes \\
\hline
\end{tabular}

Summary of observations regarding efficiency of specific steps in metastasis, and their dependence on the degree of malignancy of the cells. Conclusions are based on specific experimental results presented in the text.

inefficient. Furthermore, they found that the highly malignant cells intravasated, whereas the poorly metastatic ones failed to do so, as detected by cells in blood. Thus, the intravasation step may be inefficient and related to the malignancy of cells in the primary tumour. Interestingly, however, a recent study [33] presented evidence that cells that have been shed from a primary tumour, in an experimental colon cancer model, may have reduced malignancy relative to the parental cell line. This suggests that cells that successfully intravasate from a highly metastatic tumour cell line may not all have or retain this phenotype. Thus, detection of cells in the circulation may indicate a high degree of malignancy of the primary tumour, although the detected cells may or may not retain this property, and their presence is not necessarily predictive of risk for metastasis.

Fig. 4 presents a summary of the conclusions described above, derived from our results as well as those of other groups. We present this diagram as a point for discussion. It should be borne in mind that the dogmatic statements presented are probably over-simplifications, derived from specific experimental studies, and may not necessarily be generalizeable. However, patterns emerge from this analysis that we believe will be helpful in guiding future experiments, as well as in interpreting the potential clinical significance of cancer cells that are identified at various points in the metastatic cascade.

\section{Clinical implications of experimental studies on metastatic inefficiency}

Metastasis is responsible for most cancer mortalities, and one might thus suppose that any indication of metastatic cells would therefore justify aggressive therapy. However, the prognostic significance of individual tumour cells in blood, bone marrow, or lymph node has recently been called into question. Treatment decisions for metastatic breast cancer have been made more difficult by an increasingly sensitive ability to detect these cells, coupled with limited clinical data to assess their significance to patient prognosis $\left[3^{\circ}, 4^{\bullet}, 34,35^{\circ}, 36^{\circ}\right]$. Immunohistochemical techniques to detect isolated carcinoma cells or micrometastases in blood or tissues, using antibodies against epithelial markers such as cytokeratins (eg $\left.\left[3^{\circ}, 34,36^{\bullet}, 37\right]\right)$ or reverse transcription polymerase chain

\section{Figure 5}
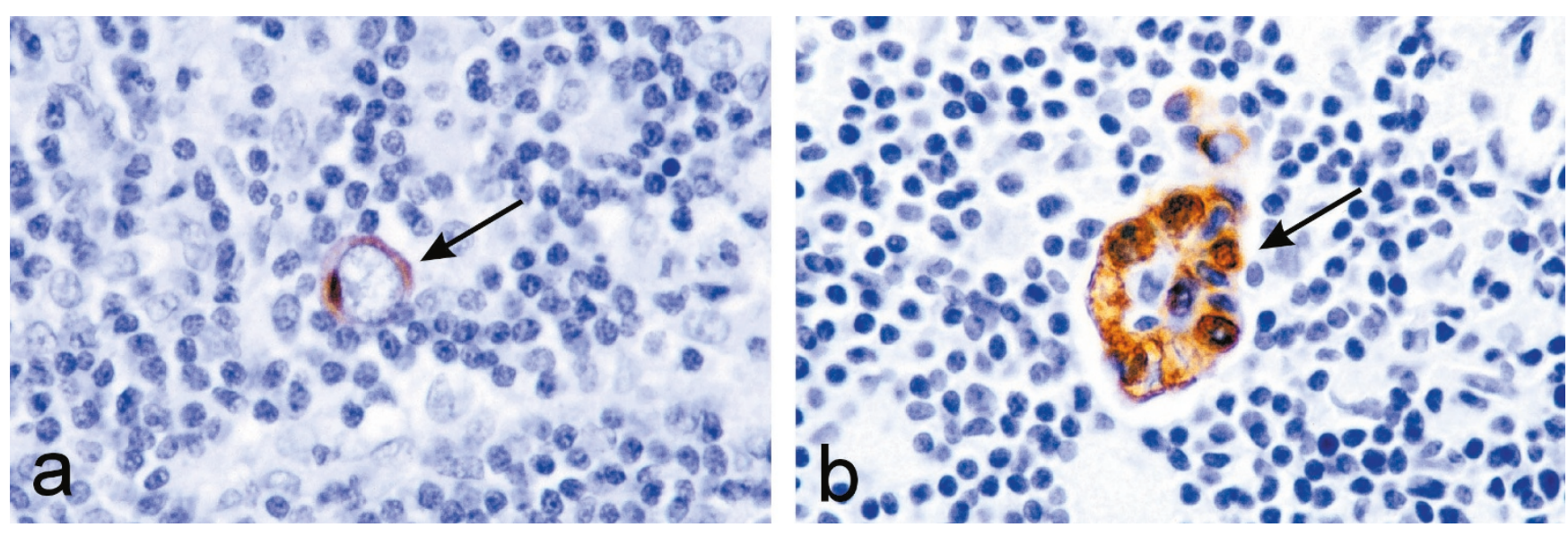

Isolated breast cancer cell and micrometastasis in sentinel lymph node. (a) Individual isolated tumour cell $(\rightarrow)$ and (b) small micrometastatic group of tumour cells $(\rightarrow)$ in the sentinel lymph node of two different breast cancer patients, as detected with anticytokeratin (AE1/AE3) antibodies $(400 \times)$. The clinical relevance of (a) versus $(b)$ is at present unclear. 
reaction assessment for various markers that are thought to be specific for cancer cells [38-41], have shown that such cancer cells can be detected in many patients. However, the clinical significance of these cells remains controversial and poorly understood $\left[3^{\circ}, 4^{\bullet \bullet}, 35^{\circ}, 42-44\right]$.

Fig. 5 shows an isolated tumour cell and a small group of tumour cells detected in sentinel lymph nodes of two breast cancer patients using anticytokeratin antibodies. Do such cells represent a pool of viable cancer cells that will go on to form clinically important metastases? Alternanatively, can such cells be detected which, in some cases, are of no (or limited) negative consequences to the patient?

The experimental studies summarized herein suggest that the detection of individual tumour cells and small groups of tumour cells at distant sites does not, in itself, necessarily predict that metastases will grow in these patients. Evidence has been presented to show that such cells can readily be detected, in model systems, from nonmetastatic or poorly metastatic cell lines. As outlined in Fig. 4, there is a large degree of inefficiency and much variation between different cell lines in the steps of metastasis that must occur after the stage of detection of isolated cells and small micrometastases. Not all isolated cancer cells will go on to grow, and not all micrometastases that initiate growth will persist in growth to form clinically relevant metastases. Markers to determine which of these cells are associated with subsequent formation of macrometastases must be evaluated, and associations with clinical outcome in cancer patients must be explored. Without this information, detection of isolated tumour cells and groups of such cells in patients' blood, sentinel lymph nodes or distant sites will remain an unreliable prognostic indicator.

\section{Conclusion}

The experimental studies described above suggest that few isolated cancer cells detected in secondary sites may begin to grow, and not all micrometastases that begin growth may persist to form macrometastases. Significant inefficiency and variability in the metastatic process occur during the growth of cancer cells in secondary sites. Based on biological considerations, the presence of isolated tumor cells or cell clusters at distant sites would not, in itself, be expected to be a reliable predictor of subsequent development of macrometastases, and markers that are associated with clinical outcome must be evaluated for these cells.

\section{Acknowledgements}

We acknowledge AC Groom, IC MacDonald, VL Morris and EE Schmidt (deceased 08/19/99) - our collaborators on the videomicroscopy and metastatic inefficiency studies described herein. We also thank colleagues who generously shared reprints and unpublished manuscripts: DR Welch, CW Rinker-Schaeffer, JE Segall, JG Jones and JS Condeelis. Work by our group cited in the present review was supported by grants from the Canadian Breast Cancer Research Initiative (\#8426), the National Cancer Institute of Canada (\#8133), the Lloyd Carr-Harris Foundation and the US Army Breast Cancer Research Program (DOD DAMD 17-96-6075, Career Development Award to Dr Tuck).

\section{References}

Articles of particular interest have been highlighted as:

- of special interest

- of outstanding interest

1. Pisani P, Parkin DM, Bray F, Ferlay J: Estimates of the worldwide mortality from 25 cancers in 1990. Int J Cancer 1999, 83:18-29.

2. Pisani P, Parkin DM, Bray F, Ferlay J: Erratum: estimates of the worldwide mortality from 25 cancers in 1990. Int J Cancer 1999, 83:870-873.

3. Funke I, Schraut W: Meta-analyses of studies on bone marrow

- micrometastases: an independent prognostic impact remains to be substantiated. J Clin Oncol 1998, 16:557-566.

This is an important meta-analysis of the literature to date on the prognostic significance of isolated tumour cells in bone marrow.

4. Page DL, Anderson TJ, Carter BA: Minimal solid tumor involvement -. of regional and distant sites: when is a metastasis not a metastasis? [editorial]. Cancer 1999, 86:2589-2592.

This is an excellent editorial, which comments on [34 $4^{\circ}$ and discusses the clinical significance of micrometastases and isolated tumour cells.

5. Weiss L: Metastatic inefficiency. Adv Cancer Res 1990, 54:159-211.

6. Tarin D, Vass AC, Kettlewell MG, Price JE: Absence of metastatic sequelae during long-term treatment of malignant ascites by peritoneo-venous shunting. A clinico-pathological report. Invasion Metastasis 1984, 4:1-12.

7. Tarin D, Price JE, Kettlewell MG, Souter RG, Vass AC, Crossley B: Mechanisms of human tumor metastasis studied in patients with peritoneovenous shunts. Cancer Res 1984, 44:3584-3592.

8. Fidler IJ: Metastasis: quantitative analysis of distribution and fate of tumor emboli labeled with ${ }^{125}$ I-5-iodo-2'-deoxyuridine. J Natl Cancer Inst 1970, 45:773-782.

9. Butler TP, Gullino PM: Quantitation of cell shedding into efferent blood of mammary adenocarcinoma. Cancer Res 1975, 35:512516.

10. Liotta LA, Kleinerman J, Saidel GM: Quantitative relationships of intravascular tumor cells, tumor vessels, and pulmonary metastases following tumor implantation. Cancer Res 1974, 34:9971004.

11. Chambers AF, MacDonald IC, Schmidt EE, Koop S, Morris VL, Khokha $\mathrm{R}$, Groom AC: Steps in tumor metastasis: new concepts from intravital videomicroscopy. Cancer Metastasis Rev. 1995, 14:279-301.

12. MacDonald IC, Schmidt EE, Morris V., Groom AC, Chambers AF: In

- vivo videomicroscopy of experimental hematogenous metastasis: cancer cell arrest, extravasation and migration. In: Motion Analysis of Living Cells. Edited by Soll DR, Wessels D. New York: John Wiley and Sons, 1998:263-287.

This is a review of IVVM and cell 'accounting' procedures, with an especially technical focus.

13. Chambers AF, MacDonald IC, Schmidt EE, Morris VL, Groom AC: Preclinical assessment of anti-cancer therapeutic strategies using in vivo videomicroscopy. Cancer Metastasis Rev 1999, 17:263-269.

14. Chambers AF: The metastatic process: basic research and clinical implications. Oncol Res 1999, 11:161-168.

15. Chambers AF, MacDonald IC, Schmidt EE, Morris VL, Groom AC: - Clinical targets for anti-metastasis therapy. Adv Cancer Res 2000, 79:91-121.

This is an extensive review of findings to date using IVVM and cell 'accounting' procedures to clarify the metastatic process.

16. Koop S, MacDonald IC, Luzzi K, Schmidt EE, Morris VL, Grattan M, Khokha R, Chambers AF, Groom AC: Fate of melanoma cells entering the microcirculation: over $80 \%$ survive and extravasate. Cancer Res 1995, 55:2520-2523. 
17. Luzzi KJ, MacDonald IC, Schmidt EE, Kerkvliet N, Morris VL, Chambers AC, Groom AC: Multistep nature of metastatic inefficiency: dormancy of solitary cells after successful extravasation, and limited survival of early micrometastases. Am J Pathol 1998, 153: 865-873.

18. Morris VL, MacDonald IC, Koop S, Schmidt EE, Chambers AF, Groom AC: Early interactions of cancer cells with the microvasculature in mouse liver and muscle during hematogenous metastasis: videomicroscopic analysis. Clin Exptl Metastasis 1993, 11:377-390.

19. Morris VL, Koop S, MacDonald IC, Schmidt EE, Grattan M, Percy D, Chambers AF, Groom AC: Mammary carcinoma cell lines of high and low metastatic potential differ not in extravasation but in subsequent migration and growth. Clin Exptl Metastasis 1994, 12:357367.

20. Naumov GN, Wilson SM, MacDonald IC, Schmidt EE, Morris VL, Groom AC, Hoffman RM, Chambers AF: Cellular expression of green fluorescent protein, coupled with high-resolution in vivo videomicroscopy, to monitor steps in tumor metastasis. J Cell Sci 1999, 112:1835-1842.

21. Farina KL, Wyckoff JB, Rivera J, Lee H, Segall JE, Condeelis JS, Jones JG: Cell motility of tumor cells visualized in living intact primary tumors using green fluorescent protein. Cancer Res 1998, 58: 2528-2532.

22. Sckell A, Safabakhsh N, Dellian M, Jain RK: Primary tumor sizedependent inhibition of angiogenesis at a secondary site: an intravital microscopic study in mice. Cancer Res 1998, 58:58665869.

23. Scherbarth S, Orr FW: Intravital videomicroscopic evidence for regulation of metastasis by the hepatic microvasculature: effects of interleukin- $1 \alpha$ on metastasis and the location of B16F1 melanoma cell arrest. Cancer Res 1997, 57:4105-4110.

24. Talmadge JE, Wolman SR, Fidler IJ: Evidence for the clonal origin of spontaneous metastases. Science 1982, 217:361-363.

25. Chambers $A F$, Wilson $S$ : Use of $\mathrm{Neo}^{\mathrm{R}}$ B16F1 murine melanoma cells to assess clonality of experimental metastases in the immune-deficient chick embryo. Clin Exptl Metastasis 1982, 6: 171-182.

26. Koop S, Schmidt EE, MacDonald IC, Morris VL, Khokha, R, Grattan M, Leone J, Chambers AF, Groom AC: Independence of metastatic ability and extravasation: metastatic ras-transformed and control fibroblasts extravasate equally well. Proc Natl Acad Sci USA 1996, 93:11080-11084.

27. Welch DR: Technical considerations for studying cancer metastasis in vivo. Clin Exp Metastasis 1997, 15:272-301.

This is an excellent and comprehensive review on experimental methods used to study tumour metastasis.

28. Cameron MD, Schmidt EE, Kerkvliet N, Nadkarni KV, Morris VL, Groom AC, Chambers AF, MacDonald IC. Temporal progression of metastasis in lung: cell survival, dormancy, and location dependence of metastatic inefficiency. Cancer Res 2000, 60:2541-2546.

29. Welch DR, Steeg PS, Rinker-Schaeffer CW: Molecular biology of breast cancer metastasis: genetic regulation of human breast carcinoma metastasis. Breast Cancer Res 2000, 2:408-416.

30. Chekmareva MA, Kadkhodaian MM, Hollowell CM, Kim H, Yoshida - BA, Luu HH, Stadler WM, Rinker-Schaeffer CW: Chromosome 17-mediated dormancy of AT6.1 prostate cancer micrometastases. Cancer Res 1998, 58:4963-4969.

This is an important study that demonstrates that a metastasis-suppressor gene functions by blocking growth of cells that successfully arrive at a secondary site.

31. Goldberg SF, Harms JF, Quon K, Welch DR: Metastasis-suppressed

- C8161 melanoma cells arrest in lung but fail to proliferate. Clin Exp Metastasis 1999, 17:601-617.
This paper shows that a second, unrelated metastasis-suppressor gene also functions by blocking growth of cells that successfully arrive at a secondary site (see also [30"]).

32. Wyckoff JB, Jones JG, Condeelis JS, Segall JE: A critical step in metastasis: in vivo analysis of intravasation at the primary tumor. Cancer Res 2000, 60:2504-2511.

33. Swartz MA, Kristensen CA, Melder RJ, Roberge S, Calautti E, Fukumura D, Jain RK: Cells shed from tumours show reduced clonogenicity, resistance to apoptosis, and in vivo tumorigenicity. $\mathrm{Br} J$ Cancer 1999, 81:756-759.

34. Dowlatshahi K, Fan M, Bloom KJ, Spitz DJ, Patel S, Snider HC Jr: Occult metastases in the sentinel lymph nodes of patients with early stage breast carcinoma: a preliminary study. Cancer 1999, 86:990-996.

35. Allred DC, Elledge RM: Caution concerning micrometastatic breast - carcinoma in sentinel lymph nodes [editorial]. Cancer 1999, 86: 905-907.

A good editorial is presented, which comments on the significance of [34].

36. Hermanek P, Hutter RV, Sobin LH, Wittekind C: Classification of iso- lated tumor cells and micrometastasis. Cancer 1999, 86:26682673.

This paper identifies the need to consider isolated tumour cells separately from micrometastases, and establishes a working definition of a 'micrometastasis'.

37. Racila E, Euhus D, Weiss AJ, Rao C, McConnell J, Terstappen LW, Uhr JW: Detection and characterization of carcinoma cells in the blood. Proc Natl Acad Sci USA 1998, 95:4589-4594.

38. Brown DC, Purushotham AD, Birnie GD, George WD: Detection of intraoperative tumor cell dissemination in patients with breast cancer by use of reverse transcription and polymerase chain reaction. Surgery 1995, 117:95-101.

39. Choy A, McCulloch P: Induction of tumour cell shedding into effluent venous blood breast cancer surgery. $\mathrm{Br} J$ Cancer 1996, 73: 79-82.

40. Mori M, Mimori K, Ueo H, Karimine N, Barnard GF, Sugimachi K, Akiyoshi T: Molecular detection of circulating solid carcinoma cells in the peripheral blood: the concept of early systemic disease. Int J Cancer 1996, 68:739-743.

41. Mori M, Mimori K, Ueo H, Tsuji K, Shiraishi T, Barnard GF, Sugimachi $\mathrm{K}$, Akiyoshi $\mathrm{T}$ : Clinical significance of molecular detection of carcinoma cells in lymph nodes and peripheral blood by reverse transcription-polymerase chain reaction in patients with gastrointestinal or breast carcinomas. J Clin Oncol 1998, 16:128-132.

42. Golinger RC, Gregorio RM, Fisher ER: Tumor cells in venous blood draining mammary carcinomas. Arch Surg 1977, 112:707-708.

43. Cady B: Lymph node metastases. Indicators, but not governors of survival. Arch Surg 1984, 119:1067-1072.

44. Jatoi I: Breast cancer: a systemic or local disease? Am J Clin Oncol 1997, 20:536-539.

Authors' affiliations: Ann F Chambers, George Naumov and Sharon Vantyghem (London Regional Cancer Centre, London, Ontario, Canada), and Alan B Tuck, Department of Pathology, London Health Sciences Centre, London, Ontario, Canada)

Correspondence: Ann F Chambers, PhD, London Regional Cancer Centre, 790 Commissioners Road East, London, Ontario, N6A 4L6 Canada. Tel: +519 685 8652; fax: +519 685 8646; e-mail: ann.chambers@Ircc.on.ca 